\title{
Water absorption of wood-polymer composites of savewood
}

\author{
Tatyana Matseevich ${ }^{1 *}$, Andrey Matseevich ${ }^{2}$, and Andrey Askadskii ${ }^{1,2}$ \\ ${ }^{1}$ Moscow State University of Civil Engineering, Yaroslavskoe shosse, 26, Moscow, 129337, Russia \\ ${ }^{2}$ A.N. Nesmeyanov Institute of Organoelement Compounds of Russian Academy of Sciences, \\ Vavilova St. 28, Moscow, Russia
}

\begin{abstract}
The materials based on wood-polymer composites (WPC) in the form of decking boards are produced, in which wood filler is partially replaced by mineral one. WPC materials manufactured by Savewood using a matrix polymer of polyvinyl chloride (PVC) have good mechanical properties, low abrasion and satisfactory resistance to climatic influences. However, they have relatively high water absorption, the task of reducing which is relevant not only in Russia, but also in other countries where there are constructions of facilities operating in outdoor environmental conditions. The modification of such materials in this work was carried out by replacing part of the wood filler with the mineral filler, which is $\mathrm{CaCO}_{3}$ (chalk). Partial replacement of wood flour with mineral filler resulted in a marked reduction in swelling from 1.25 to $0.01 \%$. In this case, the modulus of elasticity is increased from 2260 to $2880 \mathrm{MPa}$, tensile strength from 30.5 to values of $16.7 \div 32 \mathrm{MPa}$. The specific impact strength varies from 8.90 to $7.74 \mathrm{~kJ} / \mathrm{m}^{2}$. The optimal ratio of wood and mineral fillers is $60 / 40 \%$.
\end{abstract}

Wood-polymer composites (WPC) are increasingly used for the manufacture of products for construction purposes. The floors of the terrace rooms, siding, decorative fences, intake systems, steps, universal profiles, various accessories and components are made of them. All these materials work in conditions of climatic influences of the environment. The Russian manufacturer of products from WPC is the company Savewood. Polyvinyl chloride (PVC) is used as a matrix polymer in this company, and wood flour has been used as the filler until recently. The study of the properties of these materials is carried out in conjunction with the A.N. Nesmeyanov Institute of Organoelement Compounds RAS and the N.N. Semenov Institute of Chemical Physics RAS.

The properties of the terrace boards are studied in [1-7]. Mechanical properties such as modulus of elasticity, tensile strength, compression and bending strength, cracking resistance, hardness and specific impact strength are considered. In a number of works, WPC based on PVC was studied [8-10] and the methods of WPC manufacturing were described in [11-12]. Properties in a wide range of temperatures are described in [13], and thermal properties, water absorption, hardness, abradability, resistance to climatic influences, and the use of secondary polymers are studied in [14].

\footnotetext{
* Corresponding author: MatseevichTA@mgsu.ru
} 
First, we consider the mechanical and thermal properties, as well as the water absorption of standard WPC materials manufactured by Savewood Company. Previously, tests of WPC samples [13, 14] produced by this company were carried out, and comparisons were made with samples produced by other domestic and foreign Companies. The mechanical properties (modulus of elasticity and tensile strength, impact strength, abrasion, hardness, thermal characteristics, resistance to climatic influences) have been measured. Among the thermal characteristics are temperature dependences of deformation under the action of a small load on the sample (thermomechanical curves), thermal expansion coefficients and relaxation transitions in a wide temperature range. The climatic effects are evaluated as the action of UV-irradiation and moisture. We give a brief description of these characteristics.

For a detailed analysis of the linear thermal expansion coefficient, a TMA Q400 instrument (TA Instruments) was used to measure the sample size with a very small load on the punch, equal to $0.05 \mathrm{~g}$ [14]. The temperature dependence of the change in the dimensions of the standard sample is shown in Figure 1 over the entire temperature range studied.

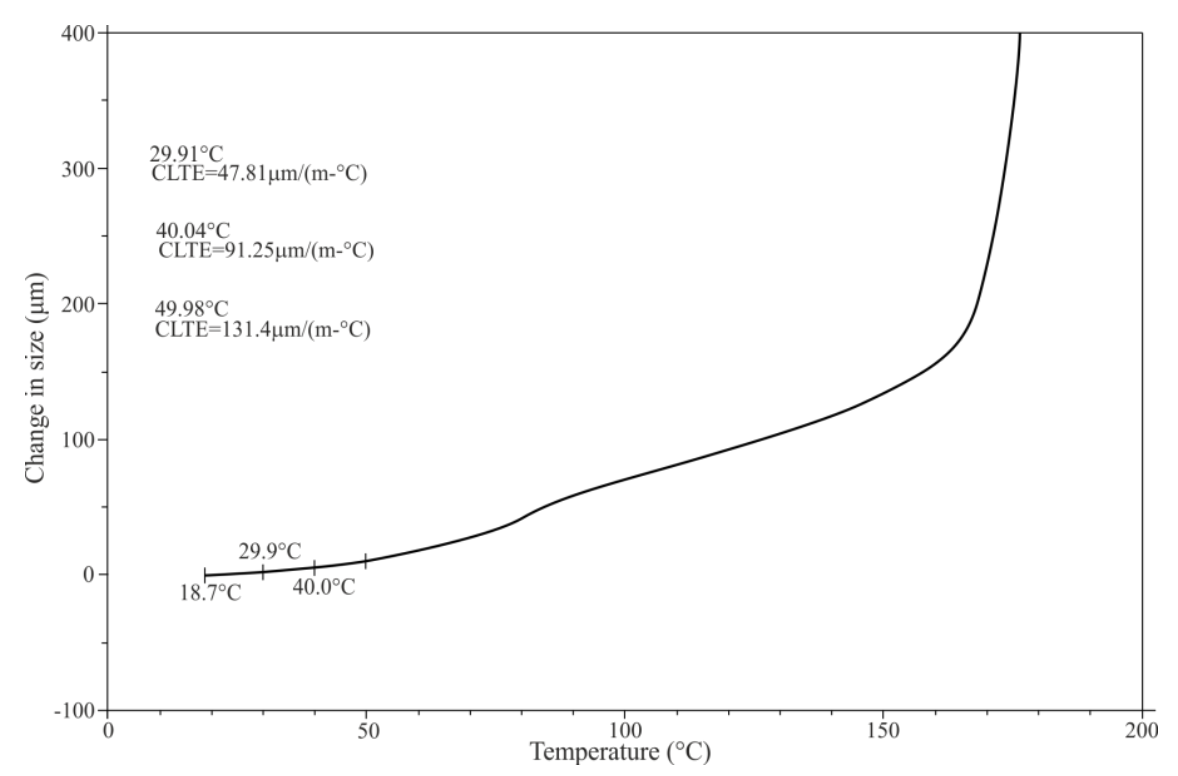

Fig. 1. The dependence of the change in the size of a standard sample produced by the manufacturer Savewood on temperature. The magnitudes of CTE in different temperature ranges are shown in the figure.

In the range of operating temperatures from -30 to $50^{\circ} \mathrm{C}$, the coefficient of thermal expansion has a small value (from 63 to $120 \mu \mathrm{m} / \mathrm{m} \cdot \mathrm{grad}$ ), characteristic of materials in which the polymer is in a glassy or semi-crystalline state.

The climatic effects are evaluated as the action of UV-irradiation and moisture. We give a brief description of these characteristics.

Table 1 shows the compositions of the WPC samples used in this work. The control sample is used from a material that does not contain mineral filler. 
Table 1. Composition of samples.

\begin{tabular}{|c|c|c|}
\hline Sample number & Chalk, $\%$ & The share of wood flour, $\%$ \\
\hline Control & 0 & 100 \\
\hline 1 & 80 & 20 \\
\hline $2 *$ & - & - \\
\hline 3 & 40 & 60 \\
\hline 4 & 40 & 60 \\
\hline (2-fold processing) & 70 & 30 \\
\hline 6 & 30 & 70 \\
\hline
\end{tabular}

*Sample No. 2 was not produced by the Savewood Company, but by another domestic company. It also contains PVC as a matrix polymer.

In the study of mechanical properties, stress-strain curves for all samples 1-6 were obtained. As an example, the stress-strain curve for sample number 3 is shown in Figure 2.

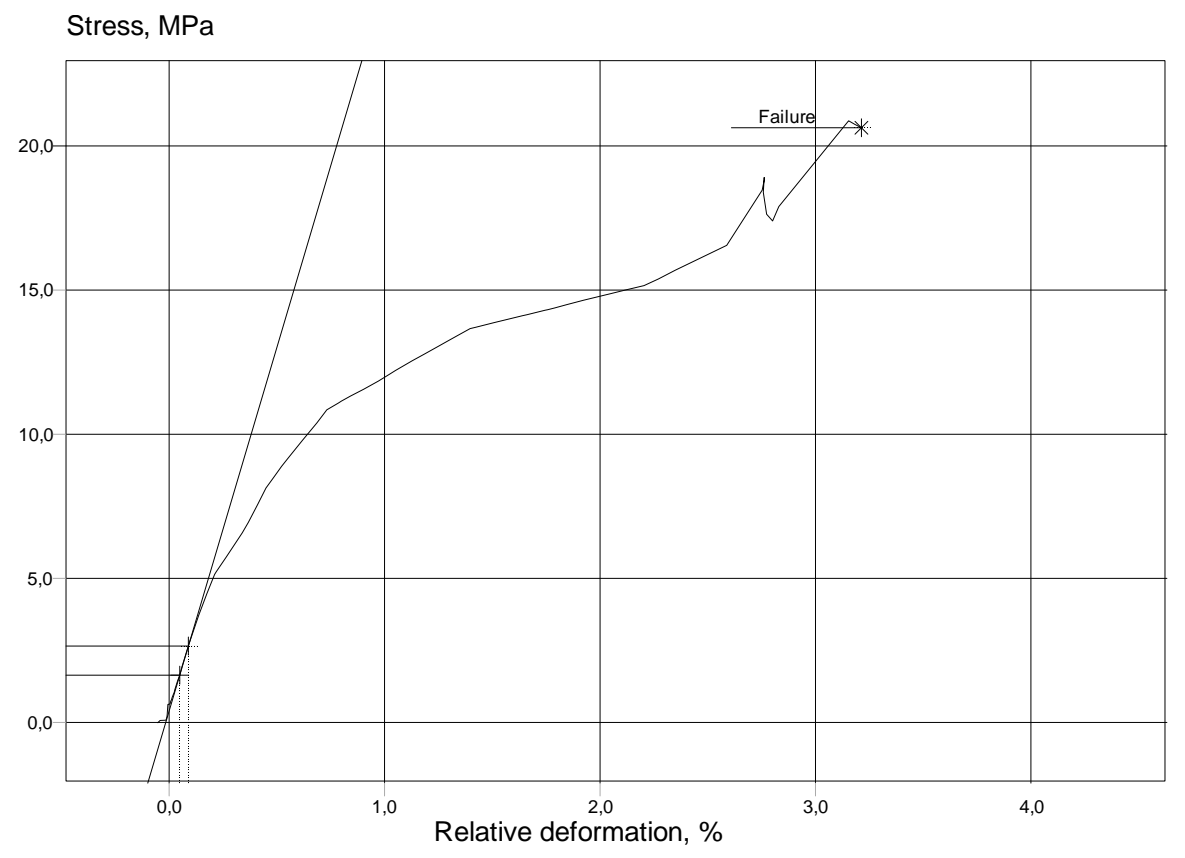

Fig. 2. The stress-strain curve of sample number 3.

The mechanical properties of the control sample and samples 1-6 are shown in Table 2. 
Table 2. Mechanical properties of the studied samples.

\begin{tabular}{|c|c|c|c|c|c|c|}
\hline $\begin{array}{l}\text { Sample } \\
\text { number }\end{array}$ & $\begin{array}{l}\text { Young's } \\
\text { modulus } \\
(\mathrm{MPa})\end{array}$ & $\begin{array}{c}\text { Stress at } \\
\text { break } \\
(\mathrm{MPa})\end{array}$ & $\begin{array}{c}\text { Relative } \\
\text { deformation } \\
\text { at rapture, \% }\end{array}$ & $\begin{array}{l}\text { Impact } \\
\text { strength, } \\
\mathrm{kJ} / \mathrm{m}^{2}\end{array}$ & $\begin{array}{c}\text { Strength } \\
\text { bending, } \\
\mathrm{MPa}\end{array}$ & $\begin{array}{c}\text { Water } \\
\text { absorption, \% }\end{array}$ \\
\hline Controle & 2260 & 30.5 & 2.47 & 8.9 & 63.9 & 1.25 \\
\hline 1 & 2050 & 18.8 & 2.73 & 3.71 & 25.0 & 0.08 \\
\hline 2 & 1750 & 24.8 & 3.37 & 6.25 & 43.7 & 0.01 \\
\hline 3 & 2160 & 16.7 & 3.40 & 6.83 & 48.1 & 0.013 \\
\hline 4 & 2420 & 23.5 & 2.65 & 7.74 & 64.8 & 0.005 \\
\hline 5 & 2880 & 32.0 & 2.57 & 3.23 & 31.8 & 0.025 \\
\hline 6 & 2680 & 26.0 & 2.07 & 4.23 & 42.7 & 0.98 \\
\hline
\end{tabular}

The study of water absorption was conducted according to GOST 4650-80 (Plastics. Methods for determining water absorption). Samples were made in the form of a square with a side equal to $(50 \pm 1) \mathrm{mm}$ and a thickness equal to the thickness of the material. The cut surface was smooth. The following equipment was used: Liquid thermostat with an error of temperature control of $\pm 1.0^{\circ} \mathrm{C}$, type TC-16, a desiccator according to GOST 25336, a vessel of enameled steel, the measuring device for determining the sample size (length, thickness) with a measurement error of not more than $0.1 \mathrm{~mm}$, water distilled according to GOST 6709, phosphorus pentoxide, laboratory scales for general use according to GOST 24104 2nd accuracy class with the maximum weighing limit of $200 \mathrm{~g}$.

Before testing, the samples were dried at $(50 \pm 2)^{\circ} \mathrm{C}$ for $(24 \pm 1) \mathrm{h}$, and then cooled in a desiccator over a desiccant at $(23 \pm 2)^{\circ} \mathrm{C}$. After cooling, the samples were removed from the desiccator, weighed, measured length, width and thickness. After that, the samples were immersed in distilled water and kept at $(23 \pm 2)^{\circ} \mathrm{C}$ for $(24 \pm 1)$ hours. After that, the samples were removed from the water, rubbed with a clean dry cloth and weighed again 
and measured in length, width and thickness. The mass fraction of water absorbed by the sample, in percent, was calculated by the formula:

$$
x=\frac{m_{2}-m_{1}}{m_{1}} \cdot 100 \%
$$

where $\mathrm{m}_{1}$ is the mass of the sample before immersion in water, $\mathrm{m}_{2}$ is the mass of the sample after extraction from water.

Swelling in directions of length, width and thickness of the samples in percent, was calculated by the formula:

$$
\alpha=\frac{x_{2}-x_{1}}{x_{1}} \cdot 100 \%
$$

where $\mathrm{x}_{1}$ is the value of the sample size before immersion in water in given direction, $\mathrm{x}_{2}$ is the value of the sample size after extraction from water in the same direction.

The results of the tests are shown in comparative Table 3.

Table 3. The values of water absorption and swelling in three directions for the studied samples.

\begin{tabular}{|c|c|c|c|c|c|c|c|}
\hline & $\begin{array}{c}\text { Control } \\
\text { sample } \\
\text { Savewood }\end{array}$ & $\begin{array}{c}\text { Sample } \\
\text { №1 }\end{array}$ & $\begin{array}{c}\text { Sample } \\
\text { №2 }\end{array}$ & $\begin{array}{c}\text { Sample } \\
\text { №3 }\end{array}$ & $\begin{array}{c}\text { Sample } \\
\text { №4 }\end{array}$ & $\begin{array}{c}\text { Sample } \\
\text { №5 }\end{array}$ & $\begin{array}{c}\text { Sample } \\
\text { №6 }\end{array}$ \\
\cline { 2 - 8 } \\
$\begin{array}{c}\text { Water } \\
\text { absorptio } \\
\text { n,\% }\end{array}$ & 1.25 & 0.08 & 0.01 & 0.013 & 0.005 & 0.025 & 0.98 \\
\hline $\begin{array}{c}\text { Swelling } \\
\text { in } \\
\text { length,\% }\end{array}$ & 0.12 & 0.02 & 0.04 & 0.02 & 0.004 & 0.014 & 0.06 \\
\hline $\begin{array}{c}\text { Swelling } \\
\text { width,\% }\end{array}$ & 0.165 & 0.02 & 0.02 & 0.02 & 0.008 & 0.018 & 0.12 \\
\hline $\begin{array}{c}\text { Thicknes } \\
\text { s } \\
\text { swelling, } \\
\text { \% }\end{array}$ & 0.94 & 0.31 & 0.55 & 0.28 & 0.47 & 0.11 & 0.68 \\
\hline
\end{tabular}

The first conclusion is that the total water absorption for a control sample produced by Savewood and not containing mineral filler is always significantly higher than the water absorption value for all other samples containing such additives.

Detailed measurements of water absorption along the length of the samples, their width and thickness were also carried out. In all cases, water absorption in different directions, estimated from the change in sample size after exposure to water, is always less for samples containing mineral additives in the form of chalk.

Experiments on water absorption and swelling over various periods of time have also been carried out. The measurement results are summarized in tables 4 and 5. It can be seen that long-term water absorption and swelling are substantially less for modified samples containing mineral filler than for a standard sample with a short exposure to water. 
Table 4. Water absorption after aging for 84 hours (3.5 days).

\begin{tabular}{|c|c|}
\hline & $\begin{array}{c}\text { Sample number 4 } \\
5 \text { mm thick }\end{array}$ \\
\cline { 2 - 2 } Water absorption, \% & 0.016 \\
\hline Swelling in length, $\%$ & 0.007 \\
\hline Swelling width,\% & 0.052 \\
\hline Thickness swelling,\% & 0.67 \\
\hline
\end{tabular}

Table 5. Water absorption after soaking for 264 hours (11 days).

\begin{tabular}{|c|c|c|}
\hline & $\begin{array}{c}\text { Sample number 3 } \\
\text { 3 mm thick }\end{array}$ & $\begin{array}{c}\text { Sample number 4 } \\
5 \text { mm thick }\end{array}$ \\
\hline Water absorption,\% & 0.06 & 0.03 \\
\hline Swelling in length,\% & 0.10 & 0.01 \\
\hline Swelling width,\% & 0.10 & 0.06 \\
\hline Thickness swelling,\% & 0.84 & 0.87 \\
\hline
\end{tabular}

In assessing the quality of materials, it is necessary to take into account not only the amount of water absorption, but also a change in other properties as a result of the introduction of a mineral additive. According to our measurements, the best combination of mechanical properties (modulus of elasticity, tensile strength and bending, elongation at break, specific toughness) and water absorption reveals sample number 3 . This sample contains $40 \%$ chalk and $60 \%$ wood flour as the filler. This sample has a very low water absorption, surpassing many other studied samples in this characteristic, or almost as good as them.

Thus, we can recommend the optimal ratio of filler components in the form of $40 \%$ chalk and $60 \%$ wood flour, leading to a significant decrease in water absorption while maintaining good mechanical characteristics.

This work was financially supported by the Ministry of Education and Science (state task \# 7.6666.2017/8.9). All tests were carried out using research equipment of The Head Regional Shared Research Facilities of the Moscow State University of Civil Engineering.

\section{References}

1. P. A. Moroz, Al. A. Askadskii, T. A. Matseevich, E. V. Solovyova, A. A. Askadskii, Plasticheskie massy, 9-10, 56-61 (2017)

2. T. A. Matseevich, A. A. Askadskii, Stroitel'stvo: nauka i obrazovanie, 7(3), 48-59 (2017)

3. T. Matseevich, A. Askadskii, IOP Conf. Ser.: Mater. Sci. Eng., 456, 012055 (2018)

4. T. Matseevich, E3S Web of Conferences, 33, 02075 (2018)

5. T. Matseevich, A. Askadskii, IOP Conference Series: Materials Science and Engineering, 365(4), 042010 (2018)

6. A. V. Abushenko, I. V. Voskoboinikov, V. A. Kondratyuk, Delovoi zhurnal po derevoobrabotke, 4, 88-94 (2008)

7. M. P. Walcott, K. A. Englund, A technology review of wood-plastic composites 3 ed. (N.Y.: Reihold Publ. Corp., 1999) 
8. Under edition. R. F. Grossman translation from English under the editorship of V. V. Guzeev, The guide to development of compositions on the basis of PVC (Scientific bases and technologies, 2009)

9. G. Kickelbick, Introduction to hybrid materials (Hybrid Materials: Synthesis, Characterization, and Applications. Weinheim: Wiley-VCH Verlag GmbH \& Co. $\mathrm{KGaA}, 2007$ )

10. Ch. Wilkie, J. Summers, Daniyels of H. Polivinilkhlorid (per. s angl. pod red. G.E. Zaikova. The polyvinylchloride translation from English under the editorship of G.E. Zaikov. Saint Petersburg. Professiya, 2007)

11. V. P. Stavrov, A. V. Spiglazov, A. I. Sviridenok, International Journal of Applied Mechanics and Enginnering, 12(2), 527-536 (2007)

12. O. Figovsky, Yu. Borisov, D. Beilin, Scientific Israel - Technological Advantages, 14(1), 7-12 (2012)

13. T. A. Matseevich, A. A. Askadskii, Construction Materials, 1-2, 101-105 (2018)

14. T. A. Matseevich, A. A. Askadskii, Construction Materials, 3, 55-61 (2018) 